\title{
Opioid substitution treatment is linked to reduced risk of death in opioid use disorder
}

\author{
(क) $($ I) $\Theta$ OPEN ACCESS \\ Sustained engagement in treatment is vital, particularly in the first "golden month"
}

\author{
Ajay Manhapra physician and lecturer ${ }^{12}$, Robert Rosenheck professor ${ }^{2}$, David A Fiellin professor ${ }^{2}$ \\ ${ }^{1}$ VA Hampton Medical Center, Hampton, VA, USA; ${ }^{2}$ Yale School of Medicine, New Haven, CT, USA
}

Deaths related to the "epidemic" of opioid use disorder are inescapable realities in communities across North America, with tags like "the American Carnage" and "this generations' AIDS crisis" in the lay press. Prescription opioids, heroin, and, more recently, fentanyl have all contributed to a precipitous rise in deaths related to opioid overdose. ${ }^{1}$ The global burden of opioid use disorder also continues to rise. Opioid substitution treatment (or the preferred term opioid agonist treatment ${ }^{2}$ ) with long acting opioids such as methadone or buprenorphine, the most effective evidence based approach, has emerged as the prominent tool in response to this public health challenge. ${ }^{3}$ Long term treatment of opioid use disorder with another opioid might evoke skepticism and concern among policymakers, patients, families, communities, and even physicians, potentially limiting participation in treatment and posing a challenge to public health.

In a linked paper, Sordo and colleagues (doi:10.1136/bmj.j1550) aggregated data on the mortality benefits of engagement with opioid substitution treatment and the harms associated with disengagement. ${ }^{4}$ Their well conducted systematic review includes long term follow-up from the highest quality observational cohort studies of treatment with methadone and buprenorphine for opioid use disorder.

The key finding that opioid substitution treatment is associated with decreased mortality should be reassuring to everyone. During methadone treatment, both all cause and overdose mortality were substantially and significantly lower than during periods of treatment disengagement (11.3 versus 36.1 all cause deaths and 2.6 versus 12.7 overdose deaths per thousand people per year). Buprenorphine treatment was associated with similar mortality benefits, but smaller research cohorts limited the robustness of the findings, raising the need for additional data.

The notable strengths of this study include a focus on all cause deaths in addition to deaths from overdose and attention to the time varying nature of opioid use disorder and its treatment, which allowed the authors to identify specific times associated with greater risk of death. They also highlight the need for data from resource poor regions and note methodological shortcomings that future research should cover.

The finding that the risk of death is highest during the initial four weeks of treatment merits attention. Many patients start treatment when the severity of their disorder crosses an unmanageable threshold - usually after prolonged use of opioids and other substances-when there is little chance of spontaneous remission and a high risk of death..$^{5-7}$ The excess mortality during the early treatment period is reduced by persistent engagement with opioid substitution treatment and increased by dropping out. This suggests a "golden month" for opioid substitution treatment, similar to the "golden six hours" observed in the care of sepsis. ${ }^{8}$

Additional measures, including overdose prevention, reduction of organizational and structural barriers to treatment entry and retention, and a singular focus on engagement with treatment during this "golden month," could help to save more lives. Earlier treatment ${ }^{7}$ before times of crisis, aggressive outreach, and risk mitigation strategies focused on the first four weeks after disengagement with treatment, when the mortality risk is heightened, could also reduce risk, but the effectiveness of these strategies have yet to be tested.

Although buprenorphine substitution treatment is associated with slightly lower rates of retention than methadone substitution, ${ }^{9}$ the current study suggests that buprenorphine could lower the risk of mortality more than methadone, especially in the vulnerable first four weeks. As cautioned by the authors, this finding is preliminary, but it does have some pharmacological validity because of the ceiling effect of the partial agonist buprenorphine and its longer duration of action and weaker cardiac effects compared with methadone. ${ }^{1011}$

The comparative benefits and harms of buprenorphine and methadone substitution need further exploration in larger studies, but practitioners might want to consider Sordo and colleagues' preliminary analyses and discuss their findings with patients 
when making the choice. As noted by the authors, cautious dose escalation is key in the use of methadone, and stepped care strategies that include buprenorphine induction with subsequent transfer to methadone show promise. ${ }^{12}$

The North American opioid epidemic, fueled by overprescribing of opioids for chronic pain, should inform international prevention efforts. ${ }^{13}$ US companies are looking toward international markets. ${ }^{14}$ In this context, advocating for more opioid prescribing, in the form of methadone or buprenorphine, might seem counterintuitive until one considers the evidence of improved outcomes, including lower HIV transmission, improved social functioning, and reduced criminal behavior, associated with opioid substitution treatment. ${ }^{15}$ Adding to this, the work of Sordo and colleagues suggest a considerable mortality benefit.

With the clear identification of the heightened mortality risks in the first month of opioid substitution treatment that could be reduced substantially by persisting with treatment, easily implementable evidence based protocols and programs to treat opioid use disorder aggressively during this "golden month" - similar to those made against sepsis ${ }^{8}$ and medical errors ${ }^{16}$ - could well increase the number of lives saved by two specific opioids, methadone and buprenorphine.

Competing interests: We have read and understood the BMJ Group policy on declaration of interests and declare that DF has advised a consultancy firm on the risk of diversion and misuse of buprenorphine Provenance and peer review: Commissioned; not externally peer reviewed.

1 Rudd RA, Seth P, David F, Scholl L. Increases in Drug and Opioid-Involved Overdose Deaths - United States, 2010-2015. MMWR Morb Mortal Wkly Rep 2016;357:1445-52. doi:10.15585/mmwr.mm655051e1 pmid:28033313.

2 Samet JH, Fiellin DA. Opioid substitution therapy-time to replace the term. Lancet 2015;357:1508-9. doi:10.1016/S0140-6736(15)60750-4 pmid:25933278.
3 Presidential Memorandum -- Addressing Prescription Drug Abuse and Heroin Use. 2015. https://obamawhitehouse.archives.gov/the-press-office/2015/10/21/presidentialmemorandum-addressing-prescription-drug-abuse-and-heroin

4 Sordo L, Barrio G, Bravo MJ, et al. Mortality risk during and after opioid substitution treatment: systematic review and meta-analysis of cohort studies. BMJ 2017;357:j1550.

5 Grella CE, Stein JA. Remission from substance dependence: differences between individuals in a general population longitudinal survey who do and do not seek help. Drug Alcohol Depend 2013;357:146-53. doi:10.1016/i.drugalcdep.2013.05.019 pmid:23791039.

6 Blanco C, Iza M, Rodríguez-Fernández JM, Baca-García E, Wang S, Olfson M. Probability and predictors of treatment-seeking for substance use disorders in the U.S. Drug Alcohol Depend 2015;357:136-44. doi:10.1016/j.drugalcdep.2015.01.031 pmid:25725934.

7 Buster MC, van Brussel GH, van den Brink W. An increase in overdose mortality during the first 2 weeks after entering or re-entering methadone treatment in Amsterdam. Addiction 2002;357:993-1001. doi:10.1046/j.1360-0443.2002.00179.x pmid:12144602.

8 Dellinger RP, Levy MM, Rhodes A, et al. Surviving Sepsis Campaign Guidelines Committee including the Pediatric Subgroup. Surviving sepsis campaign: international guidelines for management of severe sepsis and septic shock: 2012. Crit Care Med 2013;357:580-637. doi:10.1097/CCM.0b013e31827e83af pmid:23353941.

9 Mattick RP, Breen C, Kimber J, Davoli M. Buprenorphine maintenance versus placebo or methadone maintenance for opioid dependence. Cochrane Database Syst Rev 2014;(2):CD002207.pmid:24500948.

10 Vormfelde SV, Poser W. Death attributed to methadone. Pharmacopsychiatry 2001;357:217-22. doi:10.1055/s-2001-18032 pmid:11778141.

11 Chou R, Cruciani RA, Fiellin DA, et al. American Pain Society Heart Rhythm Society. Methadone safety: a clinical practice guideline from the American Pain Society and College on Problems of Drug Dependence, in collaboration with the Heart Rhythm Society. J Pain 2014:357:321-37. doi:10.1016/i.jpain.2014.01.494 pmid:24685458.

12 Kakko J, Grönbladh L, Svanborg KD, et al. A stepped care strategy using buprenorphine and methadone versus conventional methadone maintenance in heroin dependence: a randomized controlled trial. Am J Psychiatry 2007;357:797-803. doi:10.1176/ajp.2007. 164.5.797 pmid: 17475739

13 Weisberg DF, Becker WC, Fiellin DA, Stannard C. Prescription opioid misuse in the United States and the United Kingdom: cautionary lessons. Int J Drug Policy 2014;357:1124-30. doi:10.1016/j.drugpo.2014.07.009 pmid:25190034.

14 Ryan H, Girion L, Scott G. OxyContin goes global- "We're only just getting started". LoS Angeles Times. Dec 16, 2016.

15 Gowing L, Farrell MF, Bornemann R, Sullivan LE, Ali R. Oral substitution treatment of injecting opioid users for prevention of HIV infection. Cochrane Database Syst Rev 2011;(8):CD004145.pmid:21833948.

16 Berwick DM, Calkins DR, McCannon CJ, Hackbarth AD. The 100,000 lives campaign: setting a goal and a deadline for improving health care quality. JAMA 2006;357:324-7. doi:10.1001/jama.295.3.324 pmid:16418469.

Published by the BMJ Publishing Group Limited. For permission to use (where not already granted under a licence) please go to http://group.bmj.com/group/rights-licensing/ permissions

This is an Open Access article distributed in accordance with the Creative Commons Attribution Non Commercial (CC BY-NC 4.0) license, which permits others to distribute remix, adapt, build upon this work non-commercially, and license their derivative works on different terms, provided the original work is properly cited and the use is non-commercial. See: http://creativecommons.org/licenses/by-nc/4.0/. 